\title{
As incertezas como narrativa do imprevisível: o real e o complexo
}

\author{
Alfredo Pena-Vega ${ }^{1}$ \\ https://orcid.org/0000-0002-4151-9146 \\ Izabel Petraglia ${ }^{2}$ \\ https://orcid.org/0000-0002-9003-8998
}

\section{Resumo}

Este artigo, se propóe a apresentar e refletir sobre quatro diferentes modos de explicar fenômenos complexos: a questão epistêmica, a subjetividade da ameaça, o mal diante da negação e a incerteza como narrativa do imprevisível. A metodologia é bibliográfica de natureza reflexiva e a base teórica respalda-se na epistemologia da complexidade, de Edgar Morin e outros autores. Apresentamos e discutimos duas catástrofes existenciais: as mudanças climáticas e a pandemia de Covid-19 que assolam a humanidade e nos mostram as imprevisibilidades diante da ciência e das açóes humanas. $O$ texto coloca a educação como perspectiva de autoanálise e autocrítica para a transformação da realidade e aposta na esperança de ecologização das práticas e das ideias para o enfrentamento dos desafios da contemporaneidade. Considerando ainda, os Objetivos de desenvolvimento sustentável, da ONU, com respeito, solidariedade e fraternidade, os autores entendem que talvez seja possível um mundo melhor, com mais justiça social, cidadãos mais participativos e sujeitos mais felizes.

Palavras-chave: Incertezas, Pensamento complexo, Covid-19, Mudanças climáticas, Justiça social.

\section{Uncertainties as a narrative of the unpredictable: the real and the complex}

\section{Abstract}

This article aims to present and reflect on four different ways of explaining complex phenomena: the epistemic question, the subjectivity of the threat, the evil in the face of negation and uncertainty as a narrative of the unpredictable. The methodology is bibliographic

${ }^{1}$ Doutor em Sociologia pela Universidade de Paris VII - Jussieu. Professor e Pesquisador em socio-ecologia no Institute Interdisciplinaire d'Anthropologie du Contemporain - Centre Edgar Morin, EHESS-CNRS (França). Diretor cientifico do programa, Global Youth Climate Pact. E-mail: alfredo.pena-vega@ehess.fr.

${ }^{2}$ Pós-Doutora pelo Centre Edgar Morin, EHESS/CNRS, França. Doutora em Educaçáo pela USP. Professora do Programa de Pós-Graduaçáo em Educaçáo da Universidade Metodista de São Paulo - UMESP (Brasil) e líder do Grupo de Estudos e Pesquisas em Complexidade - GEPEC/UMESP-CNPq. E-mail: izabelpetraglia@terra.com.br. 
of a reflexive nature and the theoretical basis is based on the epistemology of complexity, by Edgar Morin and other authors. We present and discuss two existential catastrophes: climate change and the Covid-19 pandemic that plague humanity and show us the unpredictability in the face of science and human actions. The text places education as a perspective of self-analysis and self-criticism for the transformation of reality and bets on the hope of greening practices and ideas to face the challenges of contemporary times. Also considering the UN Sustainable Development Goals, with respect, solidarity and fraternity, the authors understand that perhaps a better world is possible, with more social justice, more participative citizens and happier subjects.

Keywords: Uncertainties, Complex thinking, Covid-19, Climate change, Social justice.

\section{Resumen}

Este artículo tiene como objetivo presentar y reflexionar sobre cuatro formas distintas de explicar fenómenos complejos: la cuestión epistémica, la subjetividad de la amenaza, el mal ante la negación y la incertidumbre como narrativa de lo impredecible. La metodología es bibliográfica de carácter reflexivo y la base teórica se basa en la epistemología de la complejidad, de Edgar Morin y otros autores. Presentamos y discutimos dos catástrofes existenciales: el cambio climático y la pandemia Covid-19 que azotan a la humanidad y nos muestran la imprevisibilidad frente a la ciencia y las acciones humanas. El texto sitúa la educación como una perspectiva de autoanálisis y autocrítica para la transformación de la realidad y apuesta por la esperanza de prácticas e ideas ecológicas para afrontar los desafíos de la actualidad. También considerando los Objetivos de Desarrollo Sostenible de la ONU, con respeto, solidaridad y fraternidad, los autores entienden que quizás sea posible un mundo mejor, con más justicia social, ciudadanos más participativos y sujetos más felices.

Palabras-clave: incertidumbres, pensamiento complejo, covid-19, cambio climático, justicia social.

\section{Introduçáo}

"No novo tempo, apesar dos perigos Da força mais bruta, da noite que assusta, estamos na luta Pra sobreviver, pra sobreviver, pra sobreviver. Pra que nossa esperança seja mais que a vingança Seja sempre um caminho que se deixa de herança. No novo tempo, apesar dos castigos De toda fadiga, de toda injustiça, estamos na briga Pra nos socorrer, pra nos socorrer, pra nos socorrer (...)." (Ivan Lins, Novo tempo, 2004)

"O que é o pior que poderia acontecer?" - "What's the worst that could happen?" é a pergunta feita em um artigo de Mary Margaret, K. Hesse, intitulado: "The world should think better about catastrophic and existential 
risks", no The Economic (25 de junho de 2020). Segundo a autora, "o mundo deveria pensar mais cuidadosamente sobre os riscos catastróficos e existenciais".

Ainda nessa perspectiva, "Em 2 de setembro de 1859, C.F. Herbert, que estava prospectando ouro no sudeste da Austrália, viu algo sublime no céu noturno. Uma cena de beleza quase indescritivel se apresentava, luzes de todas as cores inimagináveis saíam do céu do sul", ele se lembraria mais tarde. O racionalista e o panteísta viram a natureza em seus vestidos mais requintados. Os supersticiosos e os fanáticos tinham palpites terríveis e pensavam que isso anunciava o Armagedom e a dissolução final. A extinção humana é um tema onipresente nos mitos e escritos religiosos (SOAGE, 2009, p. 375-377). E mais recentemente, este tema da extinção foi retomado pelos seguidores da tese de colapso, para quem a humanidade já está em seu ponto de inflexão, que é a questão principal da civilização.

Sem querer fazer aqui qualquer referência ao aspecto mitológico do fim do mundo e muito menos às teses dos colapsólogos, devemos entender o que foi realmente que aconteceu num passado próximo ou distante? Devemos resistir à tentação de tratar eventos excepcionais como tendo "um significado mais profundo, como a cruel, mas justa punição infligida à humanidade por sua exploração impiedosa de outras formas de vida na Terra" (ZIZEK, 2020, p.19). Pois não é a vingança dos deuses, nem "a natureza se vingando da forma como os humanos a maltratam" (DUPUY, 2020). Também não se trata de punição divina, como a peste foi interpretada na Idade Média, ou de desigualdades sociais, como a cólera foi explicada no século XIX (KECK, 2010).

O que nos interessa aqui é ver se os desastres, seja o aquecimento global ou o do coronavírus - Covid-19 - podem ser uma lente através da qual se possa compreender melhor o sentimento imprevisível que pesa sobre nossa biosfera. Sua própria complexidade - a complexidade de analisar toda subjetividade nos leva a questionar a capacidade real de um indivíduo compreender seu senso de risco existencial (JEUDY-BELLINI, 2004).

Este artigo se propõe também a apresentar e abrir o diálogo sobre quatro diferentes modos de explicação de fenômenos complexos: a questão epistêmica, a subjetividade da ameaça, o mal diante da negação e a incerteza como narrativa do imprevisível. A metodologia é de natureza bibliográfica, uma leitura reflexiva sobre o tema, e a base teórica respalda-se na epistemologia da complexidade, de Edgar Morin. Refletiremos sobre a 
Educação como perspectiva de autoanálise e autocrítica para a transformação da realidade e apostamos na esperança de ecologização das práticas e das ideias para o enfrentamento dos desafios da contemporaneidade.

Devemos entender as condições científicas, sociais, políticas e éticas que tornaram possível o Covid-19, ser um dos desastres mais significativos de nossa geração em termos de seu imediatismo. Como afirma a epígrafe, da música de Ivan Lins, apesar dos perigos, estamos na luta pra sobreviver? E pra nos socorrer também? Será que vamos aprender a enfrentar o imprevisível diante dos problemas planetários? Como lidar com esses desastres? É uma espécie de desastre em cascata, como sugere Susan Cutter (2018)?

De fato, a melhor maneira de caracterizar desastres em cascata, como argumenta a autora (2018), é considerá-los como eventos extremos que podem desencadear outros eventos que muitas vezes são mal compreendidos em termos de evolução e, para os quais não temos previsibilidade. Neste tempo de imprevisibilidade, quando várias crises (sanitária, ecológica, social, econômica, tecnológica, etc.) são combinadas, finalmente começamos a reconhecer que a complexidade do desastre tem valor científico e antropológico. Não é mais um evento que causa outro evento, mas um conjunto de fenômenos complexos.

É neste sentido que veríamos a abertura de uma forma de colocar o problema da inteligibilidade de eventos excepcionais como um esquema explicativo. Entretanto, embora haja provas suficientes do tipo de explicação, não temos certeza de que tenhamos aprendido com a experiência recente, $\mathrm{e}$ muito menos de que sejamos capazes de integrar imediatamente todos os tipos de incertezas. Concordamos com as observaçóes de Toby Ord em seu livro, The Precipice (2020), de que não seríamos capazes de antecipar desastres potenciais que não têm precedentes em nossa memória coletiva. Quando os cientistas estimam uma probabilidade significativa de um evento sem precedentes, temos muita dificuldade de acreditar até que realmente o experimentamos. A ilustração deste último ponto é tanto o exemplo do aquecimento global quanto a atual crise do coronavírus.

Tomemos primeiro o caso da trajetória das emissóes de gases de efeito estufa $\left(\mathrm{CO}^{2}\right)$, mais de trinta anos depois, "podemos questionar a validade de cenários prospectivos" (LEPETIT, 2020). Durante todo este tempo, os cientistas não pararam de alertar com a ajuda de modelos probabilísticos sobre os efeitos devastadores da mudança climática com o $\mathrm{CO}^{2}$. Temos 
testemunhado cada vez mais, situações extremas, e o que os cientistas estáo propondo de cenário em cenário está entre a probabilidade previsível e a imprevisível.

Alguns se perguntam: por que as respostas à mudança climática são mais lentas e contraditórias do que as respostas a outros problemas da sociedade (colapso econômico, crise alimentar, epidemia, buraco de ozônio, etc.)?

De acordo com Peter Agre,

"é diferente porque o início não é imediato. É o imediatismo e os efeitos sobre os indivíduos que fazem da ameaça de uma epidemia um problema que temos que enfrentar rapidamente, enquanto que a mudança climática sempre foi projetada a longo prazo". (AGRE, 2017, p. 62).

Longo prazo, significa 40, 60, 100 anos, quando tudo será diferente e, boa parte das geraçóes atuais não estará mais por perto.

Não pretendemos aqui, elucubrar sobre o que vai acontecer no futuro, mas, podemos refletir sobre alternativas que a humanidade já possa estar vivenciando. O nosso futuro de humanidade é imprevisível? Podemos prever algo nesta imprevisibilidade?

Para responder a estas perguntas, vamos apresentar dois exemplos de catástrofe existencial. $\mathrm{O}$ primeiro exemplo de desastre existencial diz respeito à evolução inexorável da concentração de $\mathrm{CO}^{2}$, a fuga em termos de fenômenos extremos, cujo ponto de ruptura se multiplica a um ritmo irreversível. Este é, de fato, um cenário de catástrofe no sentido de que pela primeira vez a ameaça de devastação global não é mais uma história de ficção científica. Toby Ord é mais matizado, "reconhecendo que a mudança climática pode levar a 'uma calamidade global de proporçôes sem precedentes'", mas ele não está convencido de que represente um risco existencial real para a humanidade (ou para a civilização). Isto não quer dizer que não seja uma preocupação urgente, apenas que nossa sobrevivência ainda não está em jogo. (ORD, 2020).

O segundo exemplo se refere à natureza global da pandemia, considerando que para algumas pessoas esta crise é um momento revelador em vários aspectos. Um aspecto psicológico é a ansiedade pela apreensão do desconhecido, a preocupação de algo grave que inevitavelmente acontecerá. 
Mas, "como superar a ameaça imediata, mas também que tipo de mundo vamos habitar quando a tempestade passar" (HARARI, 2020, p.1). Será que a tempestade vai passar? O mais terrível é que precisamente agora o inevitável está acontecendo. $\mathrm{O}$ outro aspecto significativo desta crise global de saúde revela que devemos agir "no conhecimento explícito de nosso não-conhecimento" (HABERMAS, 2020). Dia após dia, todos nós temos acompanhado como os governos devem tomar decisóes na clara consciência dos limites do conhecimento dos virologistas que os aconselham. E, é verdade que nem todos os seguem! Temos alguns exemplos de países com governos autoritários e suas poucas açóes efetivas de combate à pandemia e os males causados. O Brasil, lamentavelmente, está sem um titular a frente do ministério da saúde, em plena crise sanitária de largas proporções. No governo de Jair Messias Bolsonaro, até o momento, já houve a passagem de três ministros da saúde, sendo o último, provisório, desde o mês de maio, um militar e não médico.

A complexidade ajuda na compreensão de que o estado de nosso conhecimento avança lentamente, mas agora as respostas estão disponíveis, pelo menos para algumas das questóes que a sociedade enfrenta. Como afirma Morin (1977), tudo o que não se regenera, se degenera!

\section{A invasáo epistêmica}

Esta crise nos dá uma resposta diferente - ou prova - a tudo o que teorizamos nas últimas décadas. Esta é uma grande novidade. Neste sentido, ela nos apresenta um verdadeiro desafio epistemológico: a invasão epistêmica (BALLANTYNE, 2015). De acordo com Nathan Ballantyne, a intrusão epistêmica ocorre quando um cientista vai claramente além de seu campo de estudo e fala sobre um assunto sobre o qual ele náo tem os dados ou conhecimento para avaliar as provas e/ou as variáveis. É verdade que nossas convicçôes se baseiam apenas parcialmente nas provas relevantes. Em certa medida, transgredir os limites do conhecimento exigiria um verdadeiro avanço epistêmico. Sem querer extrapolar entre, por um lado, um acúmulo abundante de conhecimentos no campo climático, dando mesmo origem a uma maior sensibilidade ecológica por parte da população, e por outro lado, um Covid-19 que não dominamos todas as interaçóes científicas, deixando em aberto o sentimento de uma ameaça nem sempre perceptível. Estamos em 
um nevoeiro, será que nosso conhecimento destes fatos poderia nos levar a pensar de forma diferente sobre nossas crenças sobre nosso futuro?

$\mathrm{O}$ advento do coronavírus sem dúvida contribuiu para uma releitura de nossa visão de mundo. Nossas certezas sobre a verdade científica foram abaladas, a ciência ainda não está certa de onde vem este vírus. Há suspeitas de ser o resultado da transmissão de animais selvagens para humanos zoonose. Tivemos algumas evidências da origem deste vírus, mas também, logo no início da pandemia, emergiu uma contraprova da validade desta tese. Um vírus transmitido de um morcego para um pangolim (animal silvestre parecido com um tatu) em um mercado em Wuhan (China) e depois para humanos ao redor do mundo. Finalmente, a tese de que o morcego teria infectado diretamente o homem prevaleceu no meio científico. Vale ainda lembrar que algumas teorias conspiratórias, que apontavam para a fabricação do coronavírus em um laboratório da cidade chinesa e, de lá se espalhado indiscriminadamente, também vieram à tona. Em entrevista recente à revista Veja (2020), o artista plástico e ativista político Ai Weiwei, reconhecido mundialmente por seu trabalho em defesa da arte e da cultura, manifestou-se acerca da teoria da criação do vírus no laboratório. Para o chinês, radicado em Portugal, "O argumento não soa tão conspiratório para mim. Não me convence a explicação de que o coronavírus teria surgido da natureza ou em um mercado de animais, como se diz" (p. 14). As certezas, mais uma vez são questionadas! $\mathrm{Ai}$ Weiwei reconhece que em Wuhan há o mais famoso centro de pesquisas epidemiológicas do País e acrescenta que, a China “(...) nunca o abriu para o mundo, nem esclareceu quais virus e doenças estavam sendo estudados ali. A falta de transparência da China sobre o que ocorria naquele laboratório torna compreensivel que as pessoas desconfiem" (idem, ibdem).

$\mathrm{O}$ que sabemos, no entanto, é que após alguns meses da propagação deste coronavírus na cidade de Wuhan, de fato, mais de 27 milhóes de pessoas foram infectadas e quase 900.000 pessoas já morreram, no mundo (COVID19 - GOOGLE NEWS, 2020) e temos mais de 60 milhóes de desempregados, sendo um número significativo deles, jovens. Só no Brasil, o início do mês de setembro já contabilizava bem mais de 120.000 mortos! E quase 9 milhões perderam o emprego, de abril a junho, em relação ao período de janeiro a março. Segundo dados do IBGE - Instituto Brasileiro de Geografia e Estatística, em 2020 o Brasil bateu record histórico, com o 
aumento de 15,6\% de desempregados, desde 2012, quando iniciou a série de pesquisas. (BRASIL, 2020). Uma verdadeira catástrofe!

Além da questáo puramente estatística, um assunto que as ciências humanas e sociais terão que entender muito rapidamente é o mote sociocultural, sobre o uso de máscara ser obrigatório, o comportamento de distanciamento físico, nossa percepção de risco, lidar com os medos, etc. O que é novo e, precisa ser aprendido é que esta pandemia não é apenas biológica, é agora geopolítica, financeira, econômica, ecológica, social, educacional, etc., e ainda que, não é apenas uma questão de meio ambiente. $\mathrm{E}$ aprendemos praticamente todos os dias que sofreremos consequências crescentes, a menos que comecemos agora a mudar o nosso comportamento social, ou seja, admitir que temos que ecologizar nossas práticas e ideias para um mundo melhor. No entanto, uma pergunta permanece: Qual é o significado epistêmico desses desafios para o pensamento coletivo?

Dentre os significados, destacamos a bifurcação necessária em escala global, por exemplo, em termos de valor. Esta ameaça existencial da pandemia em escala planetária deve dar origem a um novo "valor" (valor solidário, valor ecológico). Reiteramos a ideia de que "há um princípio de incerteza de que não pode ser evitada e que deve nos fazer saber que ainda estamos fazendo apostas" (MORIN, 2004, p. 95). Não podemos prever o resultado de nossas açóes a longo prazo, porque existe uma lei de imprevisibilidade.

Outro aspecto a ser levantado sobre a invasão epistêmica é o significado particular que damos a uma ameaça existencial: ameaças naturais, sanitárias, ecológicas, políticas, econômicas, éticas, ameaças e medos em escala íntima e planetária, simultaneamente. Há algo que nos faça temer sobre a nossa existência, ou que demonstre que nossa vida esteja ameaçada? Não estamos seguros disso. Náo estamos seguros sobre nada!

O que é uma ameaça existencial: crise, risco, catástrofe, colapso? Aqui encontramos uma corrente de pensamento voltada para o campo da avaliação de riscos existenciais, que abrange diferentes tipos de ameaças à humanidade: explosões estelares, super vulcóes, inteligência artificial, micróbios. Estas reflexôes vêm considerando, há algum tempo, que uma pandemia é uma das duas ameaças de desastres latentes no registro de risco do Estado, a outra seria um ataque cibernético maciço.

De acordo com Stefan Schubert e seus co-autores, "O século 21 provavelmente verá um aumento no risco de extinção humana, mas atualmente 
relativamente poucos recursos estão sendo investidos na redução destes riscos existenciais" (SCHUBERT ET AL., 2019, p.1). Como esses riscos são percebidos por um público neófilo?

Da mesma forma, uma equipe de pesquisa do Instituto do Futuro da Humanidade, da Universidade de Oxford e do Centro de Estudos de Risco Existencial, da Universidade de Cambridge, estudou a partir de três amostras (o público britânico, o público americano e estudantes britânicos) como um público desinformado aborda a questão da extinção. Enquanto as pessoas geralmente pensam que a extinção deve ser evitada, os autores acham surpreendente que não tenham uma ideia muito clara do que representaria uma catástrofe de extinção, no sentido errado da palavra. De acordo com o estudo, um número significativo de entrevistados considera a extinção particularmente ruim quando consideram (a) a extinção de uma espécie animal e não humana, (b) que a extinção humana estaria associada a menos danos diretos, e (c) que eles têm a visão de que as consequências de um tal desastre seriam a longo prazo (SCHUBERT, 2019).

Para Ord (2000), torna-se imperativo estudar cada ameaça potencial e examinar a probabilidade de sua ocorrência ao longo do próximo século. Numa época em que estamos lidando com uma pandemia de proporçóes globais, chegou o momento de pensar no que poderia ser feito para evitar um futuro caótico. De acordo com Anthony: "o periodo que estamos vivendo é um momento crítico na história humana" (ANTHONY, 2020).

Finalmente, o imediatismo do evento com o qual fomos confrontados com o problema da epidemia do coronavírus; diferindo da trajetória da emissão de $\mathrm{CO}^{2}$, é a questão do comportamento imprevisível dos agentes infecciosos (KECK, 2010) dá uma importância primordial ao postulado de inteligibilidade. "Se as mutaçôes de vírus são fenômenos biológicos contínuos, as reaçôes que provocam nos organismos por onde passam são descontínuas" (KECK, 2010, p. 11). Muitos cientistas, virologistas, epidemiologistas e até mesmo antropólogos advertiram que uma epidemia global iria eclodir em algum momento no futuro próximo, que já se tornou presente!

Como aponta Douglas Kennedy (2020), ainda há um problema fundamental: como escrever sobre algo cujas repercussôes a longo prazo ainda são desconhecidas? Neste grande desconhecido, o problema é o princípio da incerteza. Como afirma Morin, "a incerteza não se resume a mediçôes e previsóes. Trata-se de conceitos capazes de levar em conta fenômenos complexos" (MORIN, 
1977, p. 379). Com relação ao covid-19, o interessante é que sua dimensão ontológica, epistemológica e antropológica se reflete, entre outras coisas, na concepção de uma relaçáo entre o corpo e a razão.

Como vimos, eventos extremos e ameaças globais, não sabemos como tratá-los, nem como nossas sociedades se organizam para lidar com situaçóes excepcionais, não podemos extrair as causas ocultas. Outra fonte de confusão é explicar a ocorrência de um evento por uma causa parcial, como se fosse necessário e suficiente para produzir o evento em questão. Quando nossas sociedades questionam a evolução do clima da Terra, devemos explicar que náo existe uma causa única, mas sim sistemas governados por múltiplas interações complexas: atmosfera e sua composição, oceanos, hidrosfera, criosfera, biosfera, comportamento humano.

Temos uma tendência de querer a todo custo identificar a causa de um fenômeno, mesmo único, a fim de dar-lhe significado e integrá-lo numa concepção global da natureza das coisas (ATLAN, 2018). Esta preocupação por uma explicação racional foi encontrada em fenômenos epidêmicos. " $A s$ epidemias fascinam, continuando a permear a memória coletiva muito depois de seu desaparecimento. Elas levantam dilemas científicos, éticos e morais, revelam desigualdades, perturbam a ordem social, e revelam interdependências globais" (GUILBAUD, SANSONETTI, 2015, p. 7). Vimos que múltiplas questóes éticas surgiram com a epidemia: a questão do cuidado, quem tem prioridade, ansiedade, medo sobre o desconhecido, ameaças de todo tipo, apreensão, tensóes sociais. Esta epidemia é, portanto, um objeto privilegiado de análise sobre a subjetividade da ameaça.

\section{Uma situaçáo agônica: a subjetividade da ameaça}

Estamos enfrentando uma grande ameaça existencial. Há uma efusão global de forças devastadoras resultantes de um modelo desumanizador e destrutivo de globalização. Sintomas de ansiedade, medo e morte estão se fundindo. Esta situação agonizante não é apenas o resultado da adição de fenômenos exclusivos da crise pandêmica, mas é também um todo que se alimenta dos ingredientes de múltiplas crises: crise de ecologia global ou planetária (desregulamentação econômica, questionamento de um modelo dominante), crise de ecologia ambiental ou natural (ameaça de devastação ecológica e mudança climática) e crise de ecologia e consciência subjetiva 
(consciência de nossa condição e emancipação humana). Isto mostra como as crises são hoje interdependentes e globais. Portanto, não há qualquer chance real de resolvê-las, a menos que implementemos uma estratégia de pensamento que seja, em si mesma, global e planetária. Esta última "só pode ser considerada se os individuos vierem a perceber que pertencem à comunidade terrestre e se perceberem como cidadãos da mesma pátria, a Terra" (MORIN, 2002, p. 69).

Temos tomado consciência de que temos um destino comum de pertencer à comunidade terrestre de vida e morte e, que, a extinção de nossa espécie é algo já inscrito na tragédia histórica da complexidade humana? Morin enfatiza a improbabilidade da vida e do pensamento, bem como o papel preponderante do acaso, da incerteza e da imprevisibilidade. Neste sentido, e longe de qualquer ilusão, para o autor,

não há paraíso passado a ser encontrado, nenhum paraíso futuro a ser construído, nenhum fim de história, nenhuma Terra Prometida, nenhum Messias a vir, nenhuma verdade não biodegradável, mas uma busca permanente em direção ao além, além de si mesmo para ir além de uma nova aventura de evolução e, se houver alguma chance, um novo nascimento do homem. (MORIN, 1977, p. 451).

Nunca antes a humanidade conheceu perigo maior. Houve muitas guerras mortais, mas hoje o perigo é total, incluindo as armas nucleares e a ameaça de um desastre ecológico com consequências imprevisíveis. "Estou preocupado", diz Martin Rees, ex-presidente da Royal Society, que cofundou o Centro de Estudos de Risco Existencial em Cambridge, "simplesmente porque nosso mundo está tão interligado que a escala dos piores desastres potenciais aumentou a niveis sem precedentes e muitas pessoas os negaram". Não sabemos, ele diz, a sábia máxima: "o desconhecido não é o mesmo que o improvável" (ANTHONY, 2020).

As crises geradas pela mudança climática e a pandemia de Covid-19 devem transformar profundamente a percepção dos tomadores de decisão e da população em geral sobre a natureza dos riscos existenciais, sua probabilidade de ocorrência e os meios de lidar com eles (GIRAUD, 2020). Não há dúvida, segundo Giraud, de que os riscos existenciais aumentarão e que a probabilidade de ocorrências aumentará. E como um bom filósofo da moral, Ord (2020) nos aconselha a diminuir o ritmo de nosso modelo 
econômico-tecnológico, a fim de nos permitir compreender suas implicaçóes em um momento em que estamos diante de verdadeiro dilema: "nada explode a não ser os smoulders de fogo, a ameaça está lá, infundindo medo e um sentimento de fragilidade em nossa existência" (ZIZEK, 2020, p. 48). O que teremos que aceitar, e o que será vital para a sobrevivência da humanidade, é um quadro mais amplo de referência sobre o que é certo e errado. Há uma tendência, segundo Ord (2020), de subestimar o futuro, e temos pouca compreensão de como nossas açóes podem afetar as milhares de geraçóes que podem vir depois de nós.

\section{O mal invisível: "uma geraçáo sacrificada"}

Propomo-nos a mostrar aqui o mal invisível da epidemia, um mal sem rosto que caracteriza a imaginação social de uma população que enfrenta incerteza imediata. Se tomarmos o caso das consequências para a saúde, o que nos impressiona como observadores, durante estes anos de crises epidêmicas (SARS em 2003, Ebola em 2014-2016, Zika em 1980-2015) é a impermeabilidade de parte da população, essencialmente as geraçôes mais jovens. Muitas histórias indicam a indolência tanto para lidar com as manifestaçôes das doenças quanto para realizar o diagnóstico médico, às vezes alarmista. Em outras palavras, existe uma espécie de disposição para acomodar (complacência) as novas ocorrências, uma apatia em relação a uma situaçáo preocupante de saúde.

O novo e notável fenômeno é que a população jovem, potencialmente menos afetada por uma patologia contaminante (vírus, radioatividade, etc.) não considera o mal como problema existencial em sua vida diária. Algumas pessoas tendem a se acostumar a ele, a não mais pensar em si mesma como um indivíduo ameaçado, mas como alguém com uma existência normal. Pensam que podem lidar com o mal. E é sobre esta percepção de "vida normal" que as repercussóes psicológicas da pandemia de Covid-19 parecem se manifestar e é aqui que a ansiedade é conscientemente potencializada. Especialmente com o aumento dos diagnósticos de saúde mental, o mal está piorando, causado pelo medo e isolamento em contexto de total insegurança.

A preocupante questáo da apatia diante de uma situaçáo de crise tem um duplo problema subjacente: alguns pesquisadores (sociólogos, psiquiatras, antropólogos, educadores) que trabalham com populaçóes após situaçóes 
extremas, como desastres nucleares, terremotos, furacóes e outras catástrofes, têm notado que surtos de ansiedade e desamparo são reações naturais que raramente se tornam traumáticas ou crônicas. Em muitos desastres as pessoas lidam bem, como afirma Steven Southwick (CAREY, 2020), que trabalhou com sobreviventes após muitos desastres. Alguns podem acreditar que são resilientes até enfrentarem circunstâncias extremas. O segundo problema que surge em situaçôes excepcionais é a consciência da responsabilidade individual e coletiva em situaçóes de crise. Segundo Hans Jonas (2000, p. 22), "quem não é diretamente ameaçado náo decide reformar radicalmente seu modo de vida", por outro lado, "assim que a ameaça se torna urgente, a situação é diferente, tanto individual como coletivamente" (JONAS, 2000, p. 22).

Como já mencionamos, as ameaças de situações extremas e/ou riscos existenciais futuros são onipresentes, às vezes mais do que uma ameaça, são sinônimos de transformação das práticas da vida diária. Além disso, as observaçóes sobre o comportamento social nesta situação de crise trazem à tona a dimensão da incerteza imediata: a mais eloquente é a situação de angústia, ansiedade que é vivida por parte dos jovens que veem nesta crise um futuro cada vez mais sombrio para sua vida futura e o sentimento avassalador de incerteza. Estamos vivendo uma situação em que o evento do coronavírus é fatal, seja pessoalmente, para um ente querido ou para alguém próximo a nós. Como podemos lidar mentalmente com algo para o qual não estávamos preparados? Até agora, estamos em um impasse. Estamos reunindo informaçôes, analisando, sondando: o que é isso? O que devemos fazer? Quando a vida pode voltar ao normal? E ainda assim, no fundo, apesar de uma ameaça premente, os estilos de vida, tanto individuais quanto coletivos, permanecem intercambiáveis?

O mal teria no comportamento social um "novo código" (SARS-Cov2) carregando um imaginário de infortúnio com o surgimento de novas consequências com uma gama de rostos perplexos. Os riscos da epidemia, assim como a mudança climática, e a fraqueza de suas respostas reforçam as incertezas. É neste sentido que devemos pensar esta nova forma de realidade. Ela deve nos permitir localizar, identificar o que pode ser descrito, percebido como maligno. Emergem sentimentos de medo diante de riscos incertos, em relação ao futuro, que podem causar angústia quando nada é perceptível e tudo parece ser imprevisível. Nesta relação, o medo de si mesmo (desordem interna) está associado a um medo do futuro (desordem do mundo). Surge 
então, a necessidade de explicar o fenômeno cognitivo e social do Mal, em particular para entender como a aparência (que significa maldade) é vivida como realidade e como conseguimos metabolizar o Mal em nossa relação com os desastres ecológicos.

O despertar de um sentimento de infortúnio é fortemente sentido em termos intergeracionais, entre os idosos, para os quais as consequências do coronavírus têm sido terríveis em termos da intensidade do número de mortes, e entre os jovens, para os quais as consequências da epidemia terão efeitos imensuráveis, particularmente no que diz respeito ao seu estilo de vida e profissional. Testemunhamos, especialmente entre os jovens, um aumento maciço da ansiedade causada por sentimento de insegurança devido à crise econômica. As dificuldades financeiras e de estilo de vida resultantes da pandemia de Covid-19 têm o potencial de desestabilizar uma juventude que já vive em contexto social precário. Em uma pesquisa realizada no final da contenção na Europa, de acordo com o think-tank inglês "Resolution Foundation", 23\% dos funcionários de 18 a 24 anos foram colocados em licença durante a contenção e $9 \%$ perderam o emprego (ADELUWOYE, 2020). Os jovens, em particular, estão preocupados com o que acontecerá após a Covid-19 e, como poderão voltar ao trabalho: "é assustador", dizem eles! Agora, o coronavírus destacou os limites de uma economia baseada no crescimento, mas o modelo ainda pretende reviver-se no altar de uma geração sacrificada, ou seja, toda uma geração de jovens presa entre uma economia cada vez mais precária, sem segurança no emprego, sem perspectivas de carreira, sem proteção social e uma situação incerta, sem oportunidades. No Brasil, especificamente, a flexibilização promovida na legislação trabalhista corrobora a amplificação dessa realidade nefasta, com permissão governamental para "acordos entre patróes e empregados", com redução de carga horária e salário, e em alguns casos, até demissão em massa. Não bastasse já o aumento significativo da terceirização da prestação de serviços fundamentais para a sociedade, com a consequente desoneração na folha de pagamento de grandes empresas e, das ameaças constantes de perda de direitos trabalhistas, conquistadas a duras penas pelos sindicatos e representantes de classes. 


\section{Incerteza como narrativa para prever o imprevisível}

Numa época em que os cientistas estão lutando para compartilhar seus conhecimentos, os eventos são muitas vezes imprevisíveis. A tragédia ecológica e humana de Chernobyl (PENA-VEGA, 2016) em 1986, na Ucrânia, bem como o triplo desastre de Fukushima, em 2011, no Japão, foram acontecimentos imprevistos. Ninguém poderia supor um desastre nuclear desse tipo no Japão. A segurança nuclear japonesa considerava que um acidente desse tipo era tecnologicamente impensável. Foi, portanto, um evento imprevisto. E finalmente vemos, que se voltarmos à história de grandes desastres, se esconde a ideia de que tudo o que era importante foi imprevisto. Finalmente, quem poderia imaginar que, pela primeira vez na história da humanidade, em escala planetária e global, "estamos encontrando algo cujo poder é muito maior do que o nosso e que consegue nos deixar parados por meses a fio" (COCCIA, 2020).

Consideramos haver sempre uma zona escura, algumas causas ocultas em fenômenos complexos. No coração desta zona escura há um princípio de incerteza e no centro do paradigma da incerteza, "há o problema da inadequação da lógica e a necessidade de uma lógica que integre o confronto dialético da contradição" (PENA-VEGA, 2018, p. 4). A incerteza está, portanto, no âmago da lógica. "Há um princípio de incerteza e, como acabamos de mencionar, há um princípio de incerteza no coração da lógica" (PENAVEGA, 2018, p. 4).

Estamos enfrentando a maior crise do século XXI e o que é interessante sobre esta palavra crise é obviamente a incerteza a que ela se refere. A questáo é como lidar com a incerteza e não como metabolizar a "colapsologia" em nossa maneira de pensar. Hoje esta multicrise é precisamente porque traz a incerteza sobre a solução. A crise é, no entanto, favorável à chegada de novas soluções. Hoje temos uma crise sanitária, uma crise em nossas relações com a biosfera, com o meio ambiente, cuja origem vem de nosso modelo econômico, que gera poluição, devastação ecológica, doenças, desigualdades, injustiças sociais. Neste cenário de caos, paradoxalmente estamos assistindo ao despertar de uma consciência adquirida por grande parte da humanidade, que compartilha um destino comum porque está exposta aos mesmos riscos existenciais (DESCOLA, 2020). 
Não sabemos se a degradação da biosfera vai aumentar, não sabemos se seremos capazes de detê-la, mas podemos ver que esta degradação está criando uma consciência da inflexão de um modelo devastador, "porque pela primeira vez a ameaça de um planeta inabitável não é mais material de ficção científica" (LEPETIT, 2020).

Estamos cientes da imensidão dos problemas que se nos colocam. Para onde vamos nesta crise inevitável entre várias formas de conceber o mundo, entre diversas formas de compreender nosso planeta? O que sairá daí? Para onde vai o mundo? (MORIN, 2010). Rumo ao abismo? (MORIN, 2011). Vemos que a previsão de imprevisibilidade, caos e complexidade é extremamente incerta. Podemos dizer que estamos enfrentando uma nova crise da humanidade? Será que estamos ultrapassados frente a esta realidade? Já tomamos consciência disso? A consciência sempre chega atrasada aos eventos!

\section{Consideraçóes finais: Educaçáo e justiça social}

Desde 2015, o mundo compartilha de uma agenda global que congrega um conjunto de 17 objetivos de desenvolvimento sustentável e 169 metas para a efetivação dos direitos humanos em todos os cantos do Planeta. Trata-se de um compromisso assumido por chefes de Estado, de Governo e altos representantes mundiais, durante o aniversário de 70 anos da Organização das Nações Unidas - ONU, em reunião realizada em Nova York, em setembro de 2015. É um desafio para todos os povos e naçóes conquistarem o desenvolvimento sustentável em sua tríplice dimensão: econômica, social, ambiental (BRASIL, 2015). Essa agenda deve estar em prática no ano $2030 \mathrm{e}$ considera, dentre outros objetivos ${ }^{3}$, acabar com a pobreza, erradicar a fome, promover o bem estar, assegurar uma educação inclusiva, equitativa e de qualidade para todos, combater a mudança climática e seus impactos, ou seja, reconhecer a igualdade de direitos de todos os seres humanos e, promover justiça social. (BRASIL, 2015).

\footnotetext{
${ }^{3}$ Ver os 17 objetivos de desenvolvimento sustentável em BRASIL. Naçōes Unidas. Transformando nosso mundo: A Agenda 2030 para o Desenvolvimento Sustentável. 13/10/2015. Disponível em : https://nacoesunidas.org/pos2015/agenda2030/\#:-:text=N\%C3\%B3s\%20resolvemos\%2C\%20entre\%20ago ra\%20e,meninas $\% 3 \mathrm{~B} \% 20 \mathrm{e} \% 20$ assegurar\%20a\%20prote $\%$ C3\%A7\%C3\%A3o
} 
Justiça social é o que garante o acesso aos bens culturais por todos os indivíduos e, além de ser um dever do Estado, é também uma construção coletiva da sociedade, em que todos os sujeitos são responsáveis. É um modo de interpretar e praticar a ética em suas três perspectivas: autoética, socioética, antropoética (MORIN, 2005) e, promover açóes de inclusão, capazes de combater as desigualdades, seja em âmbito local-comunitário ou globalplanetário.

Uma educaçáo voltada para o meio ambiente, para o despertar ecológico (PENA-VEGA, 2005) de maneira transdisciplinar, na educação básica tem papel preponderante diante das transformaçôes planetárias, tanto no Brasil quanto no mundo e sua prática marca a importância de se estabelecer açóes responsáveis e menos predatórias: ecologizadas. Vale destacar que a Educação ambiental, como campo específico, no Brasil, ainda carece de consolidação, reconhecimento e efetividade nos programas e currículos dos diversos níveis e graus do processo de escolarização. Especialmente no Brasil, as políticas públicas de Educação, Saúde, Meio Ambiente também se mostram insuficientes diante de um contexto crísico de altas proporçóes, frente a uma pandemia tal como o COVID-19, as mudanças climáticas, acirradas pelos impactos de recorrente desmatamento e depredação de nossas florestas, além de múltiplas açôes insustentáveis que nos fazem duvidar do cumprimento de uma agenda transformadora até 2030. Lamentavelmente, falta vontade e comprometimento político para a metamorfose!

A educação, compreendida aqui, como meio eficaz de aprendizagem, mudança de pensamento e de transformação social comporta uma perspectiva de autoanálise (observar o que e como fazemos algo) e autocrítica (perspectiva de mudar o que for necessário) para a transformação da realidade e manutenção da esperança na ecologização das práticas e das ideias para o enfrentamento dos desafios, cada vez mais intensos da contemporaneidade. Com respeito, solidariedade e fraternidade (MORIN, 2019, 2020) talvez seja possível um mundo melhor, com mais justiça social, cidadãos mais participativos e sujeitos mais felizes. Apostamos na Educação como brecha possível para uma cidadania terrestre em uma civilização planetária!

\section{Referências}

AGRE, P. The Real Climate Debate. Nature, v.550, p. 62-65. London, 2017. 
ATLAN, H. Cours de philosophie biologique et cognitiviste. Spinosa et la biologie actuelle. Paris: Editions Odile Jacob, 2018.

ANTHONY, A. What if Covid-19 isn't our biggest threat? 26 Abril. Science The Guardian. London, 2020.

ADELUWOYE, D. Uncertainty made me struggle: Covid puts financial stress on young people. The Guardian, agosto de 2020. London. Disponível em: https://www.theguardian.com/money/2020/aug/08/covid-financial-stressyoung-people-coronavirus-jobs Acesso em: 21 ago. 2020.

BALLANTYBE, N. The significance of unpossessed evidence. The Philosophical Quarterly, Oxford, v. 65, n. 260, p. 315-335, 2015.

BRASIL. IBGE : 2020 tem record de desemprego no Brasil. Disponível em: https://tvjornal.ne10.uol.com.br/noticias/2020/08/11/ibge-2020-temrecorde-de-desemprego-no-brasil-193188. Acesso em: 20 ago. 2020.

BRASIL. Naçóes Unidas. Transformando nosso mundo: A Agenda 2030 para o Desenvolvimento Sustentável. Disponível em : https://nacoesunidas.org/pos2015/agenda2030/\#:-:text=N\%C3\%B3s\%20re solvemos $\% 2 \mathrm{C} \% 20$ entre $\% 20$ agora $\% 20$ e,meninas $\% 3 \mathrm{~B} \% 20 \mathrm{e} \% 20$ assegurar $\%$ 20a\%20prote\%C3\%A7\%C3\%A3o Acesso em : 01 set. 2020.

CAREY, B. The mental toll of the pandemic: more waves than tsunamis. The Guardian, 21 junho. London, 2020.

COCCIA, E. La terre peut se débarrer de nous avec la plus petite de ses créatures. Le Monde, 4 abril. Paris, 2020.

COVID - 19. GOOGLE NEWS. Disponível em : https://news.google.com/covid19/map?hl=pt-BR\&gl=BR\&ceid=BR\%3Apt419. Acesso em : 09 set. 2020.

CUTTER, S. L. Compound, cascading, or complex disasters: what's in a name? Environment: science and policy for sustainable development. Londres, v. 60, n 6, p. 16-25, 2018.

DESCOLA, P. Nous sommes devenus des virus pour la planète. Le Monde, 22 mai. Paris, 2020. 
DUPUY, J. P. Notre responsabilité devient démusurée. Le Monde Idées, 4 jul. Paris, 2020.

DUVE, C. de. Poussière de vie. Une histoire du vivant. Paris: Editions Fayard, 1996.

GIRAUD, P. N. Vivre avec des risques extrêmes. Le Monde, 13 julho. Paris, 2020.

GUILBAUD, A.; SANSONETTI, P. Le retour des épidémies. Editions idées, Paris: PUF, 2015.

HABERMAS, J. Il nous faut agir dans le savoir explicite de notre non-savoir. Le Monde, 11 abril, Paris, 2020.

HARARI, Y. N. The world after coronavirus. Financial Times, 20 março. London, 2020.

HESSE, M. M. K. What's the worst that could happen? The world should think better about catastrophic and existential risks. The Economic, 25 jun. London, 2020.

JEUDY-BALLINI, M.; VOISENAT, C. Ethonographier la peur. Paris: Maison des Sciences de l'Homme, 2004.

JONAS, H. Une éthique pour la nature. Paris: Desclée de Brouwer, 2000.

KECK, F. Un monde grippé. Paris: Editions Flammarion, 2010.

KECK, F. Cette crise est un vrai défi pour la recherche. Le Monde, 8 ago. Paris, 2020.

KENNEDY, D. Le temps de l'incertitude. Le Monde, 31 mai. Paris, 2020.

LEPETIT, M. Les degrés du chaos. Le Monde, 12 jul. Paris, 2020.

LINS, I. Novo tempo. Álbum: Um novo tempo. [CD]. R.J, Brasil, EMI, 2004.

MORIN, E. La méthode. La vie de la vie. Paris: Editions du Seuil, 1977.

MORIN, E. Pensar o Milénio com Edgar Morin. Lisboa: Centro Nacional de Cultura, 2002. 
MORIN, E. Ethique de la complexité et le problème des valeurs au XXème siècle. Entretiens du XXème siècle sous la direction de Jérôme Bindé. Paris: Editions Unesco; Albin Michel, 2004.

MORIN, E. O método 6: ética. Trad. Juremir Machado da Silva. Porto Alegre: Sulina, 2005.

MORIN, E. Para onde vai o mundo? Trad. Francisco Morás. Petrópolis: Vozes, 2010.

MORIN, E. Rumo ao abismo? Ensaio sobre o destino da humanidade. Trad. Edgard de Assis Carvalho e Mariza Perassi Bosco. Rio de Janeiro: Bertrand Brasil, 2011.

MORIN, E., avec la collaboration de Abouessalam, Sabah. Changeons de voie, les leçons du coronavirus. Paris: Denoël, 2020.

ORD, T. The Precipice: Existential Risk and the Future of Humanity. London, UK: Bloomsbury Libri, 2020.

PENA-VEGA, A. O despertar ecológico. Edgar Morin e a ecologia complexa. Rio de Janeiro: Garamond, 2005.

PENA-VEGA, A. Tchernobyl, Catastrophe écologique, Tragédie humaine. Mémoire et Récit. Médis, Nova-Aquitânia: Editions Atlantique, 2016.

PENA-VEGA, A. Dialoguer avec les incertitudes. Quand le doute est une chose sûre et les connaissaces. Gazeta de antropologia, v. 33, n. 2. 2018. Disponível em: http://www.gazeta-antropologia.es/?p=5010. Acesso em: 19 ago. 2020.

SCHUBERT, S.; CAVIOLA, L. et alii. (2019). The Psychology of Existential Risk: Moral Judgments about Human Extinction. Scientific Reports Natureresearch. 2019. Disponível em: https://doi.org/10.1038/s41598-01950145-9. Acesso em : 20 ago. 2020.

SERVIGNE P. Il faut considérer la catastrophe comme certaine. Le Monde, 26 set. Paris, 2019.

SOAGE, A. B. The End of Days: Essays on the Apocalypse from Antiquity to Modernity. Jornal Totalitarian Movements and Political Religions, v. 10, n. 34, p. 375-377, 2019. 
124 Polyphonía, v. 31/1, jan.-jun. 2020

VEJA. Entrevista Ai Weiwei, por Marcelo Marthe. ed. 2702. a. 53, n. 36. set., 2020.

ZIZEK, S. Dans la tempête virale. Paris: Actes Sud, 2020.

Recebido em: 12 ago. 2020

Aceito em: 25 ago. 2020 